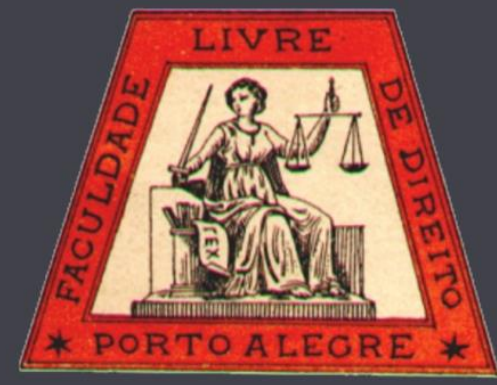

\title{
Pontos e contrapontos das concepções de justiça defendidas por Rawls e Dworkin
}

Convergence and divergence between the conceptions of justice maintained by Rawls and Dworkin

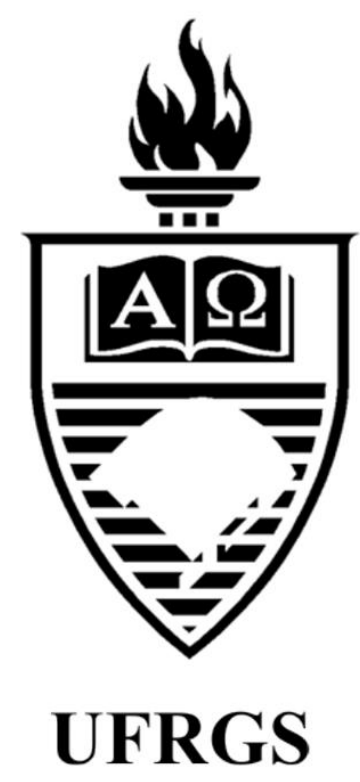

Leila Viviane Scherer Hammes Universidade de Santa Cruz do Sul 


\title{
Pontos e contrapontos das concepções de justiça defendidas por Rawls e Dworkin
}

\author{
Convergence and divergence between the conceptions of justice maintained by Rawls and Dworkin
}

Leila Viviane Scherer Hammes*

\section{REFERÊNCIA}

HAMMES, Leila Viviane Scherer. Pontos e contrapontos das concepções de justiça defendidas por Rawls e Dworkin. Revista da Faculdade de Direito da UFRGS, Porto Alegre, n. 34, p. 131-147, ago. 2016.

\section{RESUMO}

Existem pontos de convergência e de divergência entre as concepções de justiça defendidas por Rawls e Dworkin? Esse questionamento será o fio condutor do presente artigo que se baseia em pesquisa qualitativa e tem por objetivos analisar as concepções de justiça de Rawls e Dworkin e identificar pontos de convergência e de divergência entre ambas as concepções. Para tanto, será utilizada a técnica bibliográfica e o método dedutivo. O tema justiça é recorrente entre os filósofos e pensadores tendo implicação na área do Direito. Contemporaneamente, Rawls se propôs a desenvolver uma nova teoria da justiça especialmente para combater o utilitarismo, eis que não acredita nessa proposta de justiça. Inicialmente sua teoria será vista sob o enfoque moral. Para estabelecer os princípios de justiça as pessoas deveriam estar numa posição original, vestindo o véu da ignorância, para estabelecer o contrato social. A proposta rawlsiana será questionada e um dos pensadores que se propõe a fazê-lo é Dworkin. A principal crítica que este autor constrói é a de que a teoria da justiça de Rawls não respeita ou não considera os talentos e dons de cada indivíduo. Rawls considera as críticas e propõe-se a esclarecer alguns pontos destacando que sua pretensão é a de desenvolver uma concepção política de justiça. Analisadas as concepções de justiça e elementos como equilíbrio, contrato, posição original e utilitarismo, conclui-se que existem mais pontos de convergência do que de divergência nas concepções de justiça desses dois teóricos.

\section{PALAVRAS-CHAVE}

Concepções de justiça. John Rawls. Ronald Dworkin.

\begin{abstract}
Are there convergence and divergence points between the justice conceptions maintained by Rawls and Dworkin? This question will be the conducting wire of this article, which is based on qualitative research and aims to analyze the justice conceptions of Rawls and Dworkin and to identify the convergence and divergence points between both conceptions. Therefore, it will be used bibliographic technique and deductive method. The justice theme is regular among the philosophers and thinkers, having implications in the legal area. Contemporaneously, Rawls pledged to develop a new theory of justice specially to oppose the utilitarianism, once he doesn't believe in this proposal of justice. Initially, his theory will be received under the moral approach. To establish the justice principles, people should be in an original position, wearing the veil of ignorance, in order to establish the social contract. The Rawlsian proposal will be called into question and one of the thinkers that pledged to do it is Dworkin. The main critic this author builds is that Rawls's theory of justice doesn't respects or considers each person's talent and gift. Rawls considers the critics and pledges to clarify some points highlighting that his pretention is to develop a political concept of justice. Analyzing the conceptions of justice and elements such as balance, contract, original position, and utilitarianism, it is concluded that there are more convergence than divergence points between the conceptions of justice of these two authors.
\end{abstract}

\section{KEYWORDS}

Conceptions of justice. John Rawls. Ronald Dworkin.

\section{SUMÁRIO}

Introdução. 1. A concepção de justiça desenvolvida por John Rawls. 2. A concepção de justiça desenvolvida por Ronald Dworkin. 3. Pontos e contrapontos das concepções de justiça desenvolvidas por Rawls e Dworkin. Conclusão. Referências.

\footnotetext{
* Mestranda em Direito com pesquisa em Políticas Públicas de Inclusão Social (Universidade de Santa Cruz do Sul UNISC). Especialista em Gestão Universitária (Centro Universitário Univates, 2013). Graduada em Direito (Centro Universitário Univates, 2005).
} 


\section{INTRODUÇÃO}

O tema justiça é bastante instigante, assim como a sua relação com o direito. Em virtude disso, muitos pensadores buscaram definir conceitos e teorias relacionadas à justiça.

Nas últimas décadas, John Rawls foi responsável por apresentar uma teoria da justiça sob novo enfoque e desde então tem sido muito estudado e criticado. Ronald Dworkin é um desses pensadores que apresenta questionamentos à teoria da justiça rawlsiana. Nesse contexto, o presente artigo tem o propósito de analisar as concepções de justiça de Rawls e Dworkin e identificar pontos de convergência e de divergência entre ambas as concepções.

Para tanto, inicialmente serão apresentados aspectos relacionados à concepção de justiça desenvolvida por Rawls e, no segundo momento, por Dworkin. No terceiro momento serão apresentados pontos e contrapontos de ambas as concepções. Esclarece-se, por oportuno, que a concepção de justiça de Rawls será abordada de forma mais abrangente, especialmente pelo fato de ele ter se dedicado à teoria da justiça, ao passo que Dworkin se dedicou à teoria do direito - embora há também quem entenda que ele foi um teórico da justiça. Esclarece-se que conceitos não serão detalhados, pois se pretende apresentar o tema de forma dialógica, trazendo reflexões acerca das concepções de justiça, sem a pretensão de esgotar o assunto.

\section{A CONCEPÇÃO DE JUSTIÇA DESENVOLVIDA POR JOHN RAWLS}

John Rawls inaugura sua obra Uma teoria da justiça afirmando que "a justiça é a primeira virtude das instituições sociais" (RAWLS, 1997, p. 3). Analisando as relações sociais em sua prática cotidiana verifica-se, de fato, que $o$ fundamento - evidente ou de fundo - que perpassa é a justiça. Assim, ao tratar a justiça como uma virtude constata-se que é algo que não se pode dispor, pois uma virtude é algo desejável e intrínseco.

As expressões “isso é justo" ou "isso não é justo" são utilizadas comumente como juízos de valor ou para avaliar determinadas circunstâncias. Contudo, Gargarella (2008, p. 28) alerta que "a natureza não é justa ou injusta conosco, o que é justo ou injusto é o modo como o sistema institucional processa esses fatos da natureza. Daí surge sua afirmação de que a 'primeira virtude' de qualquer sistema institucional tem que ser a de sua justiça". Ou seja, o que advém da natureza, da ordem natural, não pode ser classificado em justo ou injusto. Mas, a partir do momento que esse fato da natureza sofre uma interferência do ou no sistema institucional é possível classificar o resultado como justo ou injusto, devendo-se primar pelo resultado justo. Exemplificando. Um trabalhador que sofre um acidente de trabalho e perde os movimentos de uma das mãos. $\mathrm{O}$ fato em si - perder os movimentos da mão - não poderia ser avaliado como justo ou injusto. Contudo, a partir do momento que o trabalhador fosse demitido em virtude desse acidente, há a interferência do sistema institucional. Mas, considerando que se deve primar pela justiça como primeira virtude, isto é, buscar sempre a melhor alternativa para atender a finalidade da justiça, haveria de se encontrar outra alternativa para a solução nesse contexto.

Para entender plenamente a concepção de justiça de Rawls é necessário explicitar a concepção de cooperação social da qual ela deriva, pois o que se verifica em suas obras é que ele baseia sua concepção de justiça no contrato social, a partir de Locke, Rousseau e Kant. Entretanto, Gargarella (2008, p. 18) observa que 
o contratualismo rawlsiano tem uma ideia diferente de igualdade que tem a ver com "nosso igual status moral", ou seja, a igualdade sob o aspecto moral.

Por sua vez, Weber (2010, p. 232) explica que a cooperação social rawlsiana é baseada em duas condições de possibilidade atribuídas às capacidades vinculadas à personalidade ou à qualidade moral. A primeira capacidade é a de ter senso de justiça, de ser razoável. A segunda capacidade é a de ter uma concepção de bem, de ser racional.

Constata-se que o fator razão/racionalidade está vinculado ao conceito de justiça, o que reforça a ideia de que essa concepção de justiça não advém da natureza, mas de uma construção racional. Nesse contexto,

a ideia norteadora é que os princípios da justiça para a estrutura básica da sociedade são o objeto do consenso original. São esses princípios que pessoas livres e racionais, preocupadas em promover seus próprios interesses, aceitariam numa posição inicial de igualdade como definidores dos termos fundamentais de sua associação. Esses princípios devem regular todos os acordos subsequentes; especificam os tipos de cooperação social que se podem assumir e as formas de governo que se podem estabelecer. A essa maneira de considerar os princípios eu chamarei de justiça como equidade (RAWLS, 1997, p. 12).

A partir dessa afirmação, resta evidenciado o caráter contratual na concepção de justiça de Rawls, eis que diferentes expressões remetem a essa ideia: há uma proposta e uma aceitação, existem termos e condições, há um acordo.

Porém, esse caráter contratual está no plano moral, no plano da teoria da justiça. É “um contrato muito peculiar - um contrato hipotético. Rawls refere-se, portanto, a um acordo que firmaríamos sob certas condições ideais, e no qual é respeitado nosso caráter de seres livres e iguais" (GARGARELLA, 2008, p. 15).

E essas características - livres e iguais que estarão presentes na posição original. Essa posição original é hipotética; é caracterizada pelo fato de que ninguém conhece seu lugar na sociedade, a posição de sua classe ou o status social, nem sua inteligência ou força. Então, os princípios de justiça são escolhidos sob o véu da ignorância. ${ }^{1}$ Assim ninguém seria beneficiado; a escolha aconteceria pelo acaso natural. Dessa forma os princípios da justiça são o resultado de um ajuste equitativo (RAWLS, 1997, p. 13).

A posição original possivelmente é um dos fatores mais questionados na teoria de Rawls. Weber (2010, p. 234), por exemplo, afirma que a posição original é um artifício e uma representação, um acordo hipotético e ahistórico. Por sua vez, Gargarella (2008, p. 22) esclarece que na posição original o que as pessoas de fato desconhecem é qualquer informação que diga respeito ao seu interesse, ao seu favor.

É possível depreender que a intenção de Rawls foi a de partir de um ponto neutro, sem nenhuma interferência, nenhum pré-conceito ou pré-julgamento. Daí a crítica da impossibilidade do grau zero. Portanto, acredita-se que quando Weber se refere à posição original como um artifício e uma representação, quer ressaltar que a posição original é uma estratégia adotada para compreender o sentido mais puro de justiça, por isso ocorre num plano hipotético sem um tempo histórico definido.

Entretanto, Rawls (1997, p. 24) acredita que além de hipotética a posição original é também intuitiva "de modo que, conduzidos por ela, somos levados a definir mais claramente o ponto de vista a partir do qual podemos melhor interpretar as condutas morais da forma mais adequada". A noção intuitiva possibilita visualizar o objetivo à distância.

\footnotetext{
${ }^{1}$ Rawls (1997, p. 147) explica que as partes que estão na posição original, se situam nela "atrás de um véu da ignorância. Elas não sabem como as várias alternativas irão afetar o seu caso particular, e são obrigadas a avaliar os princípios unicamente com base nas considerações gerais".
} 
Aliás, analisando essa noção intuitiva questiona-se se não seria ela uma espécie de préconceito. Talvez, em virtude disso, Rawls intuitivamente - não dê destaque ao intuicionismo.

$\mathrm{Na}$ verdade, Gargarella (2008, p. 3) observa que Rawls procura escapar do intuicionismo, mas admite a necessidade de reconhecer um lugar importante para nossas intuições na tarefa de buscar uma teoria da justiça. A oposição rawlsiana ao intuicionismo é fundamentada na "incapacidade de propor um sistema de regras capaz de hierarquizar nossas intuições (sobre qual princípio de justiça adotar em determinada situação), no caso habitual de serem gerados conflitos entre elas" (GARGARELLA, 2008, p. 2-3).

Observa-se que o intuicionismo defendido por Rawls não prevê nenhuma regra de prioridade entre os princípios. Mas afirma que é preciso "simplesmente atingir um equilíbrio pela intuição, pelo que nos parece aproximar-se mais do que é justo" (RAWLS, 1997, p. 37). Assim, "nosso objetivo deveria ser formular uma concepção da justiça que, por mais que apele para a intuição, ética ou sábia, tenda a tornar convergentes os nossos entendimentos meditados sobre a justiça" (RAWLS, 1997, p. 48). Portanto, a partir da obra Uma teoria da justiça constata-se que, ao discutir os pressupostos mais fundamentais de uma teoria, é preciso apelar para intuições compartilhadas ou à técnica do equilíbrio refletido de comparar intuições refletidas aprovadas pelo escrutínio racional.

Contudo, Rawls considera o intuicionismo um rival relativamente fraco para a sua teoria da justiça. Para ele, o utilitarismo ${ }^{2}$ é o verdadeiro fantasma da teoria da justiça, porque existe a

\footnotetext{
2 Kirste (2013, p. 147) explica que no utilitarismo clássico "a melhor ação é aquela que busca a maior felicidade para o maior número de pessoas; e a pior, aquela que, de modo semelhante, ocasiona miséria [...] o bem-estar de todos não é, entretanto, necessariamente bom para cada indivíduo: existe o risco de o valor do indivíduo ser subordinado à utilidade para o todo".
}

tendência de decidir em favor da maioria quando não se sabe como decidir. Nessas situações, de indecisão, normalmente questiona-se: qual é a proposta que satisfaz o maior número de interesses? Como consequência, apresenta-se ainda outro argumento a favor do utilitarismo que é o igualitário, em que se busca a maximização do bem-estar (GARGARELLA, 2008, p. 2-6).

Mas, o que Rawls irá questionar é se em todas as situações é justo agir em favor do interesse da maioria - afinal, qual é o espaço da minoria dentro da teoria da justiça. Por exemplo, numa situação de proliferação de um vírus contagioso, seria justo matar as pessoas contaminadas para evitar que o restante da população fosse infectado?

A crítica de Rawls consiste justamente no fato de que "o utilitarismo tende a ver a sociedade com um corpo, no qual é possível sacrificar algumas partes em virtude das restantes" (GARGARELLA, 2008, p.7-8). O utilitarismo aceita certos sacrifícios presentes, com o objetivo de obter maiores benefícios no futuro. Exemplo: "o desejo de impor sacrifícios às gerações presentes em prol de benefícios para gerações futuras" (GARGARELLA, 2008, p. 7).

Outra crítica apresentada por Rawls (1997, p. 30) é a de que "o utilitarismo não leva a sério a diferença entre as pessoas", portanto, afirma que pretende desenvolver uma teoria da justiça como alternativa ao utilitarismo.

Para a maioria dos utilitaristas a prioridade somente pode ser definida de acordo com o princípio da utilidade. Considerando que Rawls não vê nenhum problema em recorrer à intuição para resolver questões de prioridade, ele enfrenta esse problema utilizando duas maneiras simples: usando um princípio geral, a moral, ou usando uma pluralidade de princípios (RAWLS, 1997, p. 44-49). Afinal, "uma teoria da justiça é precisamente isso, uma teoria. É uma teoria de sentimentos morais [...] que estabelece os 
princípios que controlam as nossas forças morais, ou mais especificamente, o nosso senso de justiça" (RAWLS, 1997, p. 54).

Constata-se que a moral tem destaque acentuado em Uma teoria da justiça. Nas obras posteriores Rawls buscará corrigir possíveis equívocos com o intuito de desfazer más compreensões.

Ao referir-se aos princípios de justiça, Rawls (1997, p. 56) ratifica que eles podem identificar algumas condições morais que são pertinentes e, portanto, as regras de prioridade poderiam indicar a ordem de utilização dos princípios quando esses entrassem em conflito entre si.

Para tanto, refletindo sobre os elementos apresentados por Rawls, seria preciso chegar a um consenso, por meio do qual pessoas livres e em condição de igualdade definiriam de forma cooperada os termos desse acordo, isso tudo caracterizaria a justiça como equidade.

Observa-se desde logo que o autor não trata justiça e equidade como expressões sinônimas, mas equidade seria como um adjetivo de justiça. É necessário que haja esse complemento, pois não basta alcançar um resultado justo ele precisa ser equânime para de fato ser considerado justo. Enfim, "para originar um resultado justo, requer-se que criemos uma situação de equidade" (WEBER, 2010, p. 233).

Nas palavras de Rawls (1997, p. 51),

segundo o objetivo provisório da filosofia moral, pode-se dizer que justiça como equidade é a hipótese segundo a qual os princípios que seriam escolhidos na posição original são idênticos àqueles que correspondem aos nossos juízos ponderados e, assim, esses princípios descrevem o nosso senso de justiça.

Com essa afirmação Rawls define o que entende por "equilíbrio refletido". Weber (2010, p. 235), por sua vez, explica que o equilíbrio refletido consiste nos juízos refletidos dentro de certas condições favoráveis dadas pela posição original, considerando a capacidade moral dos cidadãos.

Rawls, em Uma teoria da Justiça (1997, p. 80), acredita que dois subprincípios do segundo princípio da justiça ${ }^{3}$ seriam definidos, na posição original, por consenso: quais sejam o das liberdades iguais e o princípio da igualdade este subdividido em princípio da diferença e princípio de igualdade de oportunidades. Portanto, ele defende que não cabe ao ordenamento social estabelecer e assegurar as perspectivas dos que estão em melhores condições sem que contribua com os menos afortunados.

Assim,

social and economic inequalities are to be arranged so that they are both (a) to the greatest expected benefit of the least advantaged and (b) attached to offices and positions open to all under conditions of fair equality of opportunity (RAWLS, 1999, p. 72).

Ainda no início de Uma teoria da justiça, Rawls apresenta a noção geral dos princípios, mesmo sem fazer menção expressa a eles, afirmando que

\begin{abstract}
a ideia intuitiva é a de que, pelo fato de o bem-estar de todos depender de um sistema de cooperação sem o qual ninguém pode ter uma vida satisfatória, a divisão de vantagens deveria acontecer de modo a suscitar a cooperação voluntária de todos os participantes, incluindo-se os menos bem situados (RAWLS, 1997, p. 16).
\end{abstract}

Considerando as duas afirmações destacadas verifica-se que o intuito que se pretende defender é de que as pessoas devem ser tratadas com igualdade e devem ter uma igualdade de oportunidades - mas isso não significa que elas sejam iguais. Para tanto, devese oferecer oportunidades aos menos bem situados, ou aos em posição social menos favorável, ou ainda aos menos dotados, para que

${ }^{3} \mathrm{O}$ primeiro princípio da justiça - o princípio da liberdade - seria aquele que garantiria o maior esquema possível de liberdades compatível com um igual esquema para todos. 
esses - diferentes - também estejam em situação de igualdade.

Nesse sentido, olhando para a nossa sociedade, destaca-se a importância de políticas afirmativas e inclusivas voltadas aos menos favorecidos ou menos dotados, tais como negros, índios, idosos, crianças, pessoas com deficiência, pessoas em condição de miserabilidade, entre outros. Considerando o contexto global é possível afirmar que os países que o fazem com maior mérito são também melhor desenvolvidos economicamente e culturalmente. Assim, verifica-se que ambos os princípios coexistem e complementam-se, especialmente no intuito de justiça como equidade.

Mas, em determinado momento, Rawls verifica que sua teoria de justiça não havia sido bem compreendida. Portanto, escreve Justiça como equidade. Na introdução dessa obra, esse autor explica que começou a desenvolver a ideia de que uma análise da justiça de cunho liberal seria mais bem entendida enquanto uma concepção política. Uma concepção política de justiça baseia-se em valores políticos e não deveria ser apresentada como parte de uma doutrina filosófica, religiosa ou moral. Dessa forma,

os princípios de justiça mais razoáveis seriam aqueles que fossem objeto de acordo mútuo entre pessoas em condições equitativas. A justiça como equidade é portanto uma teoria da justiça que parte da ideia de um contrato social. Os princípios que articula afirma uma concepção liberal ampla de direitos e liberdades básicos, e só admitem desigualdades de renda e riqueza que sejam vantajosas para os menos favorecidos (RAWLS, 2003, introdução).

Ao desenvolver a ideia de liberalismo político, Rawls foi levado a reformular sua exposição e defesa da teoria da justiça como equidade. Em Uma teoria da justiça, a justiça como equidade era parte de uma visão liberal abrangente, mas esta reformulação demonstra que essa teoria pode ser compreendida como uma forma de liberalismo político. Com efeito, Rawls apresenta a teoria da justiça como equidade como a forma mais razoável de liberalismo político. Assim fazendo, remodela os argumentos básicos a favor dos dois princípios de justiça, que constituem o fundamento central de uma concepção de justiça como equidade (RAWLS, 2003, introdução).

No prefácio de Justiça como equidade, constam também os objetivos que o autor tinha com essa obra sendo um deles "retificar as falhas mais graves de Uma teoria da justiça, esclarecendo como deve ser entendida a justiça como equidade". Rawls diz que na primeira obra não "discute se a justiça como equidade é uma doutrina moral abrangente ou uma concepção política de justiça". O que ele esperava com a primeira obra é que "seria razoável o leitor concluir que a justiça como equidade foi definida como parte de uma doutrina moral abrangente que poderia vir a ser desenvolvida posteriormente caso os bons resultados a isso convidassem". Com a reformulação, em Justiça como Equidade, Rawls elimina essa ambiguidade e afirma "agora, a teoria da justiça como equidade é apresentada como uma concepção política de justiça" (RAWLS, 2003, prefácio).

Weber (2010) entende que essa mudança efetuada por Rawls é fundamental, pois permite uma melhor compreensão e esclarecimento da justiça como equidade. Ele cita como exemplo a posição original, que seria mais bem entendida por meio de uma concepção política de justiça. Nesse sentido explica que

o caráter liberal da concepção política de justiça está, principalmente no fato de estabelecer essa prioridade de que gozam os direitos e liberdades fundamentais em relação às exigências do bem geral. Não se pode falar em oportunidades iguais ou que a distribuição de renda e riqueza deve beneficiar os menos favorecidos sem antes assegurar os direitos e liberdades fundamentais. Isso inclui a satisfação das necessidades básicas materiais. E, dentro do segundo princípio de justiça, 
o princípio da diferença, como princípio de justiça distributiva, está subordinado ao princípio da igualdade equitativa de oportunidades. Isso é da essência do liberalismo político defendido por J. Rawls (WEBER, 2010, p. 253).

Dessa forma, constata-se que Weber entende que a concepção de justiça, além de ser política, é liberal na medida em que protege os direitos e liberdades fundamentais. Não apenas porque tolera, mas vê como saudável a existência de diferenças.

De fato, em Justiça como equidade (2003, p. 282-285), Rawls irá nos dizer que uma sociedade bem ordenada será aquela em que seus cidadãos tiverem fins últimos em comum e que, numa concepção política de justiça, esses fins últimos são os necessários.

Logo, pode-se inferir que fins últimos necessários não se limitam somente às necessidades básicas materiais, mas também aos direitos e liberdades fundamentais, como forma de constituir uma sociedade bem ordenada.

A partir dessas considerações, percebe-se que, na obra Justiça como equidade, Rawls começa a lançar os fundamentos de Justiça $e$ democracia - obra iniciada no final de sua vida. No final do prefácio desta última obra, Rawls destaca que existem questões antigas - do período da Reforma protestante, ou antes relacionadas à democracia que precisam de resposta. Nesse sentido,

o liberalismo político tenta fornecê-la elaborando uma concepção política de justiça que seja independente e que, a partir das ideias políticas fundamentais, latentes na cultura pública de uma democracia, formule os valores políticos essenciais de um regime constitucional. Essa concepção política de justiça não pressupõe nenhuma doutrina abrangente particular. É por isso que ela funciona como um componente - um módulo, poder-se-ia dizer - que se pode acrescentar ou adaptar a numerosas doutrinas distintas ou que delas se pode derivar. Dessa forma, ela pode ser a base para um consenso, proveniente de uma superposição de doutrinas, em favor das instituições democráticas (Rawls, 2002, prefácio).
Portanto, depreende-se que a concepção política de justiça promove a justiça como equidade e obtém como resultado a democracia. Afinal,

a ideia é que, numa democracia constitucional, a concepção pública da justiça deveria ser, tanto quanto possível, independente de doutrinas religiosas e filosóficas sujeitas a controvérsias. É por isso que, na formulação de tal concepção, devemos aplicar o princípio da tolerância à própria filosofia: a concepção pública da justiça deve ser política, e não metafísica (RAWLS, 2002, p. 202).

Mas, qual seria a concepção de justiça de outros estudiosos, como Ronald Dworkin? É o que se passa a analisar.

\section{A CONCEPÇÃO DE JUSTIÇA DESENVOLVIDA POR RONALD DWORKIN}

Ronald Dworkin é um estudioso da Teoria do Direito e da Justiça, mas defende o liberalismo igualitário, com raiz em Rawls. Tem o intuito de aperfeiçoar também o igualitarismo, e deixá-lo menos imune a críticas.

Contudo, adverte que o bem deve ser analisado a partir da própria moralidade - que é um dos pontos fundamentais das suas obras. Acredita que os critérios objetivos da justiça somente podem ser analisados no seu próprio contexto de objetividade. Da mesma forma a moralidade objetiva somente existe no seu contexto de objetividade. Ao interpretar determinada norma haverá uma preconcepção moral que perpassará a análise, que poderá propiciar somente uma análise individual de bem, a partir do contexto de quem interpreta. Afinal, o que a moral requer e o que a justiça exige são aspectos diferentes da mesma grande questão (DWORKIN, 2011).

Value is one big thing. The truth about living well and being good and what is wonderful is not only coherent but mutually supporting: what we think 
about any one of these must stand up, eventually, to any argument we find compelling about the rest. I try to illustrate the unity of at least ethical and moral values: I describe a theory of what living well is like and what, if we want to live well, we must do for, and not do to, other people. That ideathat ethical and moral values depend on one another - is a creed; it proposes a way to live. But it is also a large and complex philosophical theory (DWORKIN, 2011, p. 1).

Por sua vez Gargarella (2008, p. 6) relata que Dworkin apresenta uma tentativa de mitigar algumas aparentes imprecisões da teoria da justiça e afirma que para muitos autores liberais, como Ronald Dworkin, o igualitarismo dessa postura surge do fato de que o utilitarismo considera como iguais os desiguais.

Por isso, segundo o pensamento de Gargarella, Dworkin acredita que

o único modo de o utilitarismo poder assegurar o mesmo respeito a cada indivíduo é por meio da incorporação de um conjunto de direitos, capazes de se impor a reivindicações majoritárias baseadas em preferências externas [...]. Os direitos funcionariam como limites destinados a impedir que alguma minoria sofra desvantagens na distribuição de bens e oportunidades pelo fato de uma maioria de indivíduos pensar que aqueles poucos são merecedores de benefícios menores que os recebidos pela maioria (GARGARELLA, 2008, p. 10).

Com essas palavras este autor apresenta, de certa forma, os fundamentos do princípio da diferença, na medida em que os direitos incorporados deveriam servir para propiciar igualdade. Por isso, Dworkin (1999, p. 349) também questiona o utilitarismo: "Suponhamos que os extremistas raciais sejam tão numerosos e sádicos que a tortura de um negro inocente melhorasse o nível geral de felicidade da comunidade como um todo. Isso justificaria a tortura?".

E como alternativa - ao utilitarismo Dworkin (1999, p. 353) afirma que

deveríamos, portanto, buscar um sistema de responsabilidade diferente, que também recomende o comportamento de simulação de mercado quando os direitos abstratos entrassem em conflito, mas que não pressuponha nenhum dever pessoal de agir sempre de algum modo que torne a comunidade mais feliz como um todo.

Contudo, esse sistema de responsabilidade deve ser analisado no âmbito da justiça distributiva:

\begin{abstract}
Assumimos responsabilidade por nossas escolhas de variadas maneiras. Quando essas escolhas são feitas livremente, e não ditadas ou manipuladas por outros, nós nos culpamos se concluímos que deveríamos ter escolhido de modo diverso. [...] Nossas circunstâncias são outra história: não faz sentido assumir responsabilidade por elas a não ser que sejam o resultado de nossas escolhas. Ao contrário, se estamos insatisfeitos com nossos recursos impessoais e não nos culpamos por nenhuma escolha que afetou nossa parcela nesses recursos, é natural que reclamemos que outros geralmente os oficiais de nossa comunidade foram injustos conosco. A distinção entre escolha e circunstância é não só familiar, mas fundamental em ética de primeira pessoa. [...] Não podemos planejar ou julgar nossas vidas senão pela distinção entre aquilo sobre o que devemos assumir responsabilidade, porque o escolhemos, e aquilo sobre o que não devemos porque estava além de nosso controle (DWORKIN, 2005, p. 455).
\end{abstract}

A partir do binômio escolha e responsabilidade, Dworkin defende que as pessoas são responsáveis por suas escolhas relacionadas aos recursos materiais - impessoais - e que isso, de certa forma, se deve ao esforço empreendido. Mas, ao mesmo tempo, não podem ser responsabilizadas por circunstâncias que estão além do seu controle ou mesmo da sua possibilidade de escolha. Nesse contexto, aplicase a igualdade distributiva.

Na obra Justiça para ouriços, Dworkin adverte que a distribuição é o produto das decisões dos governantes relacionadas às leis ou às políticas públicas. Ao testar a sua teoria utiliza a simulação de mercado num primeiro momento, onde as pessoas são livres para vender ou comprar a sua força de trabalho e para conseguir o que for possível nesse espaço de disputa. 
Contudo, salienta que as pessoas nem sempre são responsáveis pelo seu destino, inclusive porque não tem ingerência sobre suas heranças genéticas ou por seus talentos - percebe-se semelhança com a teoria da loteria natural defendida por Rawls. Observa também que o modelo de justiça distributiva que ele defende é somente um passo inicial para uma teoria da justiça mais generalista.

Dworkin, em dado momento da obra Uma questão de princípio, chega a escrever sobre o que a justiça não é. Talvez como forma de desconstruir sua concepção para reconstruí-la na sequência. Pois, na obra Levando os direitos a sério (2002) inclui um capítulo sobre a justiça e os direitos. Nela, aborda a questão da posição original, observando que aqueles que estiverem ocupando a posição original, para definir o contrato, devem estar de acordo com os termos desse contrato, antes de retornarem a sua posição natural (DWORKIN, 2002, p. 235).

Afinal se há conteúdo pré-acordado o contrato não seria mais original. Nesse ponto, a crítica de Dworkin é no sentido de que a posição original seria tão somente um argumento.

Possivelmente esse autor acredite que se os termos do contrato fossem firmados na posição natural poderia haver divergências ou discordâncias implicando na quebra do acordo estabelecido na posição original, pois - talvez não estariam mais livres e em pé de igualdade.

Portanto, Dworkin conclui que a

posição original de Rawls é um poderoso mecanismo de reflexão sobre a justiça, pois o intuito dessa posição incorpora e aplica a teoria da igualdade profunda [...] as partes consentem princípios de justiça sem nenhum conhecimento de quaisquer qualidades ou atributos que lhes deem vantagens sobre outros, e sem nenhum conhecimento de que concepção do bem sustentam em contraposição a outros (DWORKIN, 2001, p. 418).

Esses princípios de justiça, consentidos na posição original, não são um contrato propriamente dito, mas talvez possa ser identificado como um argumento, pois não importam as razões pelas quais os cidadãos o firmaram. Afinal, um contrato hipotético não é contrato de fato. Mas, para que os cidadãos concordassem com o contrato, deveria haver razões, ou uma força vinculadora (DWORKIN, 2002, p. 236-239).

Afinal, como identificar os princípios de justiça num grupo de pessoas livres e iguais? Dworkin (2002, p. 242-244) nos diz que pode ser relativamente difícil identificar um conjunto coerente de princípios, a partir das noções intuitivas de todos. Mas, acredita que pode acontecer que a maioria ${ }^{4}$ concorde com os dois princípios de justiça - diferença e igualdade, caracterizando assim a questão do equilíbrio reflexivo. Constata-se assim que esse autor entende ou vê com dificuldade a possibilidade de todos que estão na posição original concordarem com esses dois princípios, mas a maioria pode concordar - o que caracteriza o equilíbrio reflexivo.

Essa ideia de aceitação da maioria está vinculada à democracia. Dworkin (2001, p. 8990) trata da questão do processo e democracia e menciona que é necessário ter noção do poder político adequado para servir à concepção igualitária de democracia. Porém, é preciso distinguir entre um direito e o valor desse direito. Ao fazer essa distinção ele afirma que se inspirou na obra Uma teoria da justiça, de Rawls. Assim, acredita que

\begin{abstract}
a igualdade política exige pelo menos que todos tenham a mesma oportunidade de influenciar as decisões políticas, de modo que quaisquer impedimentos jurídicos se apliquem a todos, deixando de lado a questão de se a igualdade política também exige que as oportunidades de todos tenham o mesmo valor para cada um deles (DWORKIN, 2001, p. 90).
\end{abstract}

${ }^{4}$ Pondera-se se esse entendimento de Dworkin poderia
estar revelando um fraquejo no que tange ao utilitarismo,
pois a decisão seria a da maioria ou em prol do bem-estar da maioria. 
Nesse sentido questiona-se: é possível identificar pontos de convergência e de divergência entre as concepções de justiça desenvolvidas por Rawls e por Dworkin?

\section{PONTOS E CONTRAPONTOS DAS CONCEPÇÕES DE JUSTIÇA DESENVOLVIDAS POR RAWLS E DWORKIN}

Os filósofos Rawls e Dworkin classificamse como liberais e igualitários, mas isso por si só não significa que compartilhem das mesmas concepções de justiça. Embora Dworkin tenha se dedicado muito mais à teoria do direito do que à teoria da justiça, ele traz contribuições para fortalecer a concepção de justiça desenvolvida por Rawls.

Inicialmente serão apresentados alguns aspectos relacionados às concepções de justiça rawlsiana e dworkiniana no que dizem respeito ao equilíbrio, ao contrato, à posição original e ao utilitarismo, além de outras considerações que são oportunas. Na parte final será analisada a contribuição de Gargarella, que traça um comparativo entre esses dois autores.

Primeiro. Quando se trata da questão do equilíbrio constata-se que Dworkin (2002, p. 253-261) questiona o posicionamento de Rawls fazendo uma construção a partir de dois modelos, o natural e o construtivo. No modelo natural considera as intuições ${ }^{5}$ a partir do ponto de vista pessoal do indivíduo, com observações da realidade moral. Ao passo que o modelo construtivo considera as intuições a partir de um ponto de vista mais público num enfoque da moralidade política. Em virtude isso, Dworkin acredita que a questão do equilíbrio trazida por Rawls vai ao encontro do modelo construtivo,

\footnotetext{
${ }^{5}$ Observa-se aqui, por oportuno, que Dworkin em muitos momentos utiliza a expressão "nossos instintos" enquanto Rawls utiliza a expressão "intuição", o que demonstra a
} similitude das concepções. partindo de uma concepção particular de justiça intuição - e alcançando uma teoria geral de justiça.

Percebe-se aqui o intuito de contribuir para o aperfeiçoamento do entendimento trazido por Rawls e o próprio autor reconhece isso ao explicar o seguinte:

\begin{abstract}
É claro que na justiça como equidade não temos qualquer outro critério para julgar se uma razão é injusta, já que todos os nossos princípios são satisfeitos. Mas a razão existente pode nos incomodar e nos fazer pensar. É como se um estado de equilíbrio reflexivo estivesse um pouco abalado. Esperamos que as disparidades que possam ocorrer inscrevam-se num intervalo que não nos incomode. Agradeço a Ronald Dworkin por ter-me feito notar a necessidade de explicitar esse ponto (RAWLS, 2003, p. 96).
\end{abstract}

A partir dessa manifestação, é possível afirmar que Rawls percebe a necessidade de explicitar melhor sua concepção de equilíbrio reflexivo a partir das considerações e ponderações de Dworkin, reconhecendo que o equilíbrio pode sofrer abalos.

Segundo. Seguindo na ideia de aperfeiçoamento, Dworkin (2002, p. 273) afirma que o contrato é um excelente recurso para desenvolver a teoria da justiça, porque dá o poder do veto e o dever de cumprir as exigências. Esse autor expõe que "John Rawls, por exemplo, propõe um contrato social imaginário como meio de selecionar a melhor concepção de justiça no âmbito de uma teoria política utópica [...] os princípios de justiça de Rawls estão muito longe de exercer algum domínio" (DWORKIN, 1999, p. 233). Nesse aspecto verifica-se um ponto de divergência entre esses dois autores.

Cabe observar que Rawls ${ }^{6}$ não evidencia essa dupla funcionalidade - poder de veto e

\footnotetext{
${ }^{6}$ Rawls esclarece que a construção e reflexão apresentada por Dworkin acerca da posição original propõe "conceber a posição original e o véu da ignorância como proporcionando um modelo de força do direito natural que impele os indivíduos a uma preocupação e a um respeito
} 
cumprimento de exigências - do contrato na elaboração de sua teoria. Talvez por isso Dworkin acredite que os princípios de justiça propostos por Rawls estão longe de exercer algum domínio.

Pensando num exemplo prático, pode-se trazer a questão da reprodução medicamente assistida, que hoje é carente de legislação legal no âmbito brasileiro. Para analisar questões atinentes ao assunto, especialmente para resolver problemas relacionados a o que fazer com os embriões não utilizados nos procedimentos de inseminação artificial, recorre-se aos princípios. Mesmo em situações em que possa haver um contrato estabelecendo direitos e obrigações, como na questão da barriga solidária para um casal homossexual, caso houver alguma divergência a ser resolvida, como não há legislação regulamentando o assunto, a alternativa para chegar a uma decisão estará nos princípios, que, de certa forma, são escolhidos numa posição original, ainda que de forma intuitiva.

Retornando à posição original, Dworkin (2002, p. 276-282) observa que ela é um caso limite, pois os homens não são ignorantes, mas ignoram os seus interesses. Ou seja, não se busca benefícios particulares. Daí decorrem os direitos abstratos, quais sejam a liberdade e a igualdade. Dworkin, entretanto, apresenta uma crítica aos princípios escolhidos na posição original, pois eles não representariam um ideal igualitário.

Terceiro. Dworkin concorda com Rawls ao reconhecer que ele - Rawls - defende que o

\footnotetext{
iguais, os quais se exprimem na concepção de instituições políticas que os governam [...]. Ele acha que esse direito natural está na base da teoria da justiça como equidade e que a posição original serve de direito. É uma sugestão engenhosa, mas não a segui [...] prefiro não considerar a teoria da justiça como equidade como baseada nos direitos [...] a teoria da justiça como equidade [...] tenta estabelecer uma concepção idealizada de certas ideias intuitivas, fundamentais, como as da pessoa como ser livre e igual [...] os direitos, os deveres e os fins são apenas elementos desse tipo de concepção idealizada" (RAWLS, 2003, p. 220).
}

direito fundamental à igualdade pressupõe uma Constituição liberal. Ao mesmo tempo em que reconhece que a posição original é um poderoso mecanismo de reflexão sobre a justiça (DWORKIN, 2001, p. 418).

De fato, Rawls (2003, p. 23-24) reforça que "acordos hipotéticos não criam nenhuma obrigação, o acordo entre as partes na posição original não teria qualquer significado" e que "a importância da posição original assenta-se no fato de ser um procedimento de representação ou um experimento mental para os propósitos de esclarecimento público" (RAWLS, 2003, p. 2324).

Especificamente, na obra $O$ Liberalismo Político, reconhece-se que a posição original é somente um modelo em que as pessoas são responsáveis por seus interesses e buscam estabelecer um acordo. A posição original representa tanto a igualdade como a liberdade.

Quando se quer chegar à essência de algo, é preciso adotar uma posição de reflexão e para tanto o ponto de partida pode ser - tentar liberar a mente para construir o conceito sobre algo. Dworkin não acredita que seja possível livrar-se das preconcepções e dos pré-conceitos inerentes à pessoa. Possivelmente, por isso Rawls denomine esse contrato de hipotético e ahistórico e Dworkin afirme que os princípios de justiça escolhidos na posição original estejam muito longe de exercer algum domínio.

Quarto. Ainda é possível cogitar que em virtude disso seja tão difícil combater o utilitarismo. Verifica-se que Rawls critica o utilitarismo por possibilitar preferências ou gostos 'ofensivos', ora isso está vinculado aos pré-juízos das pessoas. Por exemplo, por gosto ofensivo, Rawls cita como exemplo o prazer que uma pessoa tem de discriminar outra ou de restringir a liberdade de outros. E nos diz que, a partir de uma perspectiva igualitária essas preferências deveriam ser condenadas ao invés de serem aceitas sem questionamento. Por sua 
vez, Dworkin faz uma crítica semelhante - ponto de convergência - no que diz respeito a esse ponto, baseando seu argumento na ideia das preferências externas. $\mathrm{Ou}$ seja, preferências relacionadas à destinação de bens para outras pessoas ou aos direitos e oportunidades que outras pessoas deveriam gozar (GARGARELLA, p. 9-10).

Verifica-se que embora sob argumentos diferentes, Rawls e Dworkin adotam crítica semelhante ao utilitarismo e sugerem que os resultados gerados pelo utilitarismo sejam questionados, especialmente a partir dos reflexos que causam para as pessoas.

Quinto. Gargarella contribui para traçar o comparativo entre esses dois autores. Ele entende que "os vínculos entre as concepções defendidas por Rawls e Dworkin em torno da justiça são claramente mais fortes que suas diferenças" (GARGARELLA, 2008, p. 65).

Esse mesmo autor, com o intuito de apresentar os vínculos existentes entre esses dois pensadores, nos diz que Dworkin desenvolve sua concepção liberal igualitária baseada em quatro aspectos que são semelhantes aos verificados na teoria rawlsiana, quais sejam: a) o liberalismo igualitário deve diferenciar a "personalidade" e as "circunstância" que envolvem as pessoas; b) a rejeição do bem-estar ou a satisfação pessoal/particular; c) a justiça é uma questão de recursos iguais; d) o liberalismo igualitário está relacionado à tolerância, à neutralidade (GARGARELLA, 2008, p. 65-66).

Mas, Gargarella (2008, p. 67) também aponta a primeira e fundamental distinção entre as duas concepções de justiça consistente no fato de que Dworkin afirma que a teoria da justiça rawlsiana é insensível aos dons de cada pessoa e não suficientemente sensível às ambições de cada um, conforme se verifica na sua explicação:

O fato de a teoria de Rawls ser insensível demais aos dons de cada um pode ser explicado do seguinte modo: os dois princípios de justiça de Rawls permitem que alguns sujeitos sejam desfavorecidos por circunstâncias que não controlam, dado que sua teoria da justiça "define a posição dos que estão pior em termos da posse de bens primários de tipo social - por exemplo, direitos, oportunidades, riqueza, etc." -, e não em termos de bens primários de tipo natural - por exemplo, talentos, capacidades mentais ou físicas etc. Essa opção leva a alguns resultados contra-intuitivos. Por exemplo, uma pessoa com salário um pouco maior que o de outra, mas com graves afecções físicas, estaria - de acordo com a teoria de Rawls - melhor que esta última, mesmo que seu salário maior não seja suficiente para pagar os remédios que necessita, devido a suas desvantagens naturais (GARGARELLA, 2008, p. 67).

Nesse caso, mesmo havendo a distribuição igualitária, as desigualdades naturais não propiciariam condição de igualdade, pois a pessoa doente não está livre dos contratempos que advém da sua condição.

A ideia de que a teoria de Rawls não é suficientemente sensível à ambição defende que as desigualdades sociais são aceitáveis se atuarem em benefício dos que estão em pior situação. Para ilustrar seu questionamento Dworkin utiliza como exemplo o fato de duas pessoas, sendo que uma trabalha muito e consegue aumentar a sua renda e a outra prefere uma vida mais tranquila e consumista. Isso acaba sendo insensível pelo fato de que a segunda pessoa se beneficia do trabalho da primeira, eis que nessa situação caberia ao governo criar um imposto para transferir recursos da primeira pessoa para a segunda, para que fiquem em condição de igualdade (GARGARELLA, 2008, p. 68). Portanto,

do ponto de vista de Rawls - assim como do ponto de vista do igualitarismo de recursos de Dworkin não seria irracional (mas, ao contrário, justo) defender um sistema institucional no qual os mais talentosos sejam levados a pôr seus talentos a serviço dos menos talentosos. Recorde-se, a esse respeito, o princípio da diferença, segundo o qual as únicas desigualdades econômicas que se justificam são aquelas destinadas a favorecer os mais desfavorecidos (GARGARELLA, p. 38-39). 
Como alternativas à proposta rawlsiana, Dworkin propõe o leilão hipotético e o seguro. No leilão todos iniciariam com um poder aquisitivo idêntico e colocariam à disposição todos os recursos impessoais. O leilão terminaria quando todos estivessem satisfeitos com os recursos que adquiriram e então receberiam uma parcela adicional e igual de recursos para a aquisição de bens e a contratação de seguro, para que lhes protegesse das desvantagens surgidas a partir das diferentes capacidades/dotes de cada pessoa (GARGARELLA, 2008, p. 69).

Contudo, Kolm (2000, p. 289) observa que essa proposta de Dworkin, para definir capacidades produtivas iguais equivalentes a um seguro fundamental, contradiz a sua intenção básica que é o recursismo e não propicia uma reflexão acerca das preferências que ele procura obter por meio desse dispositivo.

Ora se for preciso recorrer a um seguro isso pode significar que não há igualdade de recursos, pois se houvesse não seria necessário o instituto do seguro. Da mesma forma, ao passo que Dworkin defende os talentos, dons e preferências de cada um constata-se que se parte do princípio de que existe desigualdade.

Ao avaliar a questão das capacidades de troca no leilão Kolm (2000, p. 306) entende que a proposta de Dworkin é similar à de Rawls,

contudo, são muitas vezes mais extensas porque as trocas começam a partir de recursos, ao passo que, no caso de Rawls, a equalização ideal já está a meio caminho, com as rendas (e outros 'bens primários'). Isso afeta em particular os papeis das capacidades de troca e outros problemas, como o dos recursos primários indivisíveis que produzem produtos divisíveis (KOLM, 2000, p. 306).

Assim, se verifica que "Dworkin procura mostrar quais são as características que devem distinguir uma concepção igualitária plausível: as pessoas devem ter a possibilidade de iniciar suas vidas com iguais recursos materiais, e devem ter igual possibilidade de se garantir contra

eventuais

desvantagens"

(GARGARELLA, 2008, p. 70).

Nesse sentido Gargarella (2008, p. 71) explica que o propósito de Rawls e Dworkin é reduzir o peso de fatores arbitrários de um ponto de vista moral, mas o segundo autor procura aperfeiçoar pontos inadequados da concepção moral a justiça. Nesse sentido, a proposta do leilão e do seguro teria por objeto corrigir algumas falhas da proposta de Rawls, eliminando o efeito da mera sorte e mantendo os riscos das escolhas feitas pelas pessoas. O próprio Rawls (2202, p. 160) reconhece que os cidadãos iguais têm concepções diferentes e esse é um ponto crucial do liberalismo, pois essas concepções diferentes podem não se conciliar. ${ }^{7}$

Portanto, por fim, há de se considerar que Dworkin afirma que

a concepção liberal de igualdade é um princípio de organização política exigido pela justiça, não um modo de vida para indivíduos, e para os liberais, como tais, é indiferente que as pessoas prefiram manifestar-se em questões políticas, levar vidas excêntricas ou portar-se como supostamente os liberais preferem (DWORKIN, 2001, p. 303-304).

Para Rawls (2002, p. 256) essa concepção liberal da igualdade proposta por Dworkin é um exemplo de concepção política de justiça, o que confirma mais um ponto em comum entre ambas concepções de justiça.

Rawls e Dworkin. Dois teóricos que a seu modo, como que num diálogo hermeneuta - com teses, antíteses e sínteses -, trouxeram importantes contribuições para as Teorias do Direito e da Justiça.

\section{CONCLUS̃̃O}

Constata-se que Rawls desenvolve uma concepção de justiça teórica e imaginária,

${ }^{7}$ Rawls (2002, p. 160) afirma que esse é o postulado central no liberalismo e sugere que um enunciado mais recente seja buscado em Dworkin, na obra Liberalism, Cambridge Universtity Press, 1978. 
enquanto que Dworkin tenta apresentar sua concepção aplicando-a na prática, mas que, como visto, se torna tão teórica quanto a de Rawls.

Rawls desenvolve sua concepção de justiça propondo uma teoria da justiça como equidade por discordar da proposta do utilitarismo e entender que não ele não trata as pessoas como livres e iguais, ofendendo assim o propósito democrático. Para desenvolver sua teoria sugere um contrato social, imaginário e a-histórico, em que as pessoas estariam numa posição original, vestindo o véu da ignorância, para escolher os princípios de justiça.

Dworkin, por sua vez, procura muito mais aperfeiçoar a proposta de Rawls trazendo alguns novos elementos para a reflexão, como a alternativa do leilão e do seguro.

Analisando as duas concepções de justiça, constata-se que ambas apresentam muitos pontos em comum, desde o ponto de partida, vinculado ao liberalismo, passando pela rejeição ao utilitarismo e pela distribuição dos bens/recursos, dentre outros.
Há também pontos de divergência, sendo o mais crucial vinculado à questão dos talentos e dons naturais de cada pessoa.

Outros pontos de divergência visam ao aperfeiçoamento da concepção de justiça rawlsiana, como a integridade apresentada por Dworkin, quando não há correspondência entre justiça e equidade. O que se verifica também nos fatores do equilíbrio refletido, do contrato, da posição original e na concepção política de justiça é que esses fatores têm muito mais o aspecto da divergência no sentido melhor apresentar ou esclarecer esses pontos. Ainda que na questão do contrato, Rawls mantenha sua posição vinculada aos princípios de justiça, enquanto Dworkin tente trazê-la para o âmbito do direito.

De fato, esse intuito de aperfeiçoamento é relevante e notável, visto que Rawls em muitos momentos agradece a Ronald Dworkin por suas ponderações e contribuições. Essa também foi uma das razões pelas quais Rawls revisou alguns de seus conceitos, o que certamente tornou esse diálogo, composto por pontos e contrapontos, ainda mais interessante, para além da pertinência do tema - justiça.

\section{REFERÊNCIAS}

DWORKIN, Ronald. Justice for hedgehogs. Cambridge: The Belknap Press of Harvard University Press, 2011.

. A virtude soberana: a teoria prática da igualdade. Tradução Jussara Fernandes. Cidade: Editora São Paulo: Editora Martins Fontes, 2005.

. Uma questão de princípio. Tradução Luís Carlos Borges. São Paulo: Martins Fontes, 2001.

. Levando os direitos a sério. Tradução Nelson Boeira. São Paulo: Martins Fontes, 2002.

O império o direito. Tradução Jeferson Luiz Camargo. São Paulo: Martins Fontes, 1999.

GARGARELLA, Roberto. As Teorias da Justiça Depois de Rawls: um breve manual de filosofia política. Tradução Alonso Reis Freire. São Paulo: Martins Fontes, 2008. 
KIRSTE, Stephan. Introdução à filosofia do Direito. Tradução Paula Maria Nasser Cury. São Paulo: Fórum, 2013.

KOLM, Serge-Christophe. Teorias Modernas da Justiça. Tradução Simone Rezende da Silva. São Paulo: Martins Fontes, 2000.

RAWLS, John. A Theory of Justice. Cambridge: Harvard University Press, 1999. . Justiça como equidade: uma reformulação. Tradução de Claudia Berliner. São Paulo: Martins Fontes, 2003. . Justiça e democracia. Tradução Álvaro Vita. São Paulo: Martins Fontes, 2002. . O liberalismo político. Tradução Dinah de Abreu Azevedo. São Paulo: Ática, 2000. 1997. . Uma teoria da justiça. Tradução Almiro Pisetta e Lenita Esteves. São Paulo: Martins Fontes,

WEBER, Thadeu. Rawls: uma concepção política a justiça. In: TEIXEIRA, A. V.; OLIVEIRA, E. S. (Orgs). Correntes contemporâneas do pensamento jurídico. São Paulo: Manole, 2010.

Recebido em: 07/03/2016 Aceito em: 14/06/2016 
